\title{
Equality preference in the claims problem: a questionnaire study of cuts in earnings and pensions
}

\author{
Kristof Bosmans • Erik Schokkaert
}

Received: 18 January 2008 / Accepted: 6 February 2009 / Published online: 1 March 2009

(C) The Author(s) 2009. This article is published with open access at Springerlink.com

\begin{abstract}
Many distributional conflicts are characterized by the presence of acquired rights. The basic structure of these conflicts is that of the so-called claims problem, in which an amount of money has to be divided among individuals with differing claims and the total amount available falls short of the sum of the claims. We describe the results of a questionnaire in which Belgian and German students were confronted with nine claims problems. In the "Firm" version, respondents had to divide revenue among the owners of a firm who contribute to the activities of the firm in different degrees. In the "Pensions" version, they had to divide tax money among pensioners who have paid different contributions during their active career. Responses in the Pensions version are more egalitarian than in the Firm version. For both versions, the proportional rule performs very well in describing the choices of the respondents. Other prominent
\end{abstract}

We thank Bart Capéau, Frank Cowell, Luc Lauwers, Juan Moreno-Ternero, Frans Spinnewyn, Bertil Tungodden, and two anonymous referees for their valuable comments and suggestions. Any remaining shortcomings are ours. We thank Kurt De Cock, Tina Lievens, and Lars Schwettmann for practical assistance in running the questionnaire. Financial support from the Fund for Scientific

Research-Flanders (grant G.0005.04) and the Interuniversity Attraction Poles network funded by the Federal Public Planning Service, Belgian Science Policy (grant P5/21-A) is gratefully acknowledged.

K. Bosmans $(\bowtie)$

Department of Economics, Maastricht University,

Tongersestraat 53, 6211 LM Maastricht, The Netherlands

e-mail: k.bosmans@algec.unimaas.nl

K. Bosmans · E. Schokkaert

Centre for Economic Studies, Katholieke Universiteit Leuven,

Naamsestraat 69, 3000 Leuven, Belgium

E. Schokkaert

CORE, Université catholique de Louvain,

34 Voie du Roman Pays, 1348 Louvain-la-Neuve, Belgium

e-mail: erik.schokkaert@econ.kuleuven.be 
rules - in particular the constrained equal awards and constrained equal losses rulesfail to capture some basic intuitions. A substantial part of the respondents tend to become more progressive as the amount to be distributed decreases other things equal, and tend to become more progressive as the inequality in the distribution of claims becomes more unequal other things equal. All of these conclusions are robust with respect to the difference in home-country of the respondents.

\section{Introduction}

Many distributional conflicts in the real world are characterized by the presence of acquired rights. In some cases the legal system has worked out specific rules about how to settle these conflicts: examples are to be found in the sphere of bankruptcy or inheritance legislation. In other cases, however, there is no clear-cut legal solution. Important recent examples of this situation are to be found in the areas of social policy (how to cut social benefits if the budget turns out to be too low to keep all promises?) and of wage policies within a firm (which form of wage moderation is most acceptable when such moderation is made necessary by economic circumstances?). Although the legal status of the acquired rights therefore may differ considerably in different situations, all the problems mentioned before have the same basic theoretical structure. This structure can be described as follows: how ought an amount of money to be distributed among a group of individuals if these individuals have differing acquired rights, i.e., different prior claims with respect to the money, and the amount available for distribution falls short of the sum of these claims?

Psychological feelings of justice and injustice seem to be particularly strong when acquired rights are at stake. Social reactions may then have a considerable impact on the decisions taken and on their economic consequences. Of course, in actual practice, distributional conflicts are settled within a set of well-structured (legal, political, and social) institutions. Moreover, the economic agents involved in the negotiations usually are driven by self-interest and influenced by specific events and promises made in the past. These specific circumstances can only be recovered by detailed empirical research. Yet at the same time, at a more abstract level deeper ethical intuitions may also play a role. These may determine whether specific distributional solutions are in the end acceptable to the parties. They are certainly crucial for the agents that have to arbitrate in these conflicts and that in general have no immediate self-interest in the distributional conflict. It is therefore interesting to investigate the structure of these underlying ethical intuitions.

There is by now a large and rapidly growing theoretical literature on this problem-referred to as the "claims problem", "the bankruptcy problem", or the problem of "estate division". ${ }^{1}$ Formally, each claims problem is completely defined by two characteristics, viz., the vector of claims and the amount to be distributed. The literature focuses to a large extent on the axiomatic examination of rules, which associate with every claims problem a division of the amount of money among the individuals. Many of the axioms proposed in the literature have ethical content, which implies

\footnotetext{
${ }^{1}$ For overviews of this literature, see Moulin (2002) and Thomson (2003).
} 
that the rules they characterize are open to interpersonal disagreement. The question thus arises to what degree these various axioms (and therefore the various distribution rules) are found attractive by empirical subjects in solving concrete claims problems. Questionnaire studies may give interesting insights into this question of the empirical acceptance of various ethical theories. ${ }^{2}$ The results of these studies are not only relevant from a normative point of view. Investigation of the acceptance of the theoretical axioms may also offer a structured approach to explain why specific decisions are taken in the real-world examples described before.

The theoretical literature makes abstraction from the particular economic context in which the problem is situated. Knowledge of the basic characteristics of the problem, i.e., the vector of claims and the amount to be distributed, is sufficient to determine the solution. Unambiguous adherence to a rule implies that it is consistently applied to all claims problems. This is a strong requirement, as it might be possible that the acceptance of the ethical axioms is to some degree dependent on the level of the respective claims or on the amount to be distributed. Moreover, if rules are to be applied in practice, then the particular economic context is likely to be important as well, as it influences the ethical status of the characteristics of the claims problem. Therefore, from an empirical perspective, the following two questions appear to be of importance. (1) Within-context consistency: for a given economic context, to what degree do people use the same rule for different claims problems, i.e., claims problems with different claims vectors and/or available money amounts? (2) Between-context uniformity: for a given claims problem, to what degree do people propose the same division for different economic contexts?

Previous questionnaire studies on the claims problem have mainly focused on the question of between-context uniformity. Schokkaert and Overlaet (1989) confronted respondents with several versions of a claims problem. The formal characteristics of their claims problem are the same across versions, but the reason for the differences in claims varies, e.g., in one version claims reflect differences in hours worked while in another version claims reflect differences in talent. Béhue (2003) and Herrero et al. (2006) framed a given claims problem in different settings, viz, the bankruptcy, inheritance, and taxation settings. All the three studies find that the specific economic context significantly affects which divisions are favoured by the respondents. In contrast to the question of between-context uniformity, within-context consistency has received only modest attention so far. Béhue (2003) and Gächter and Riedl (2006) consider this question, but in neither study it is the main focus. ${ }^{3}$ Both studies compare only a small number of different claims problems ( 3 and 2 , respectively).

In this paper, we deal with both the question of within-context consistency and between-context uniformity. The former question is tackled by consideration of a wide variety of claims problems ( 9 in total), which are all presented to each respondent, and

\footnotetext{
2 There is an increasing interest in economics in the empirical study of the acceptance of theories of distributive justice. See Konow (2003) and Schokkaert (1999) for overviews of this literature.

3 The main contribution of the study by Gächter and Riedl (2006) is that, in addition to a questionnaire approach, it uses an experimental approach with actual negotiations. Herrero et al. (2006) also consider both questionnaire and experimental results.
} 
by giving special attention to individual-level data. The question of between-context uniformity is dealt with by using two versions of the questionnaire with the same claims problems - in the Firm version, three firm owners have to distribute a loss, and in the Pensions version, a shortage in funds has to be distributed over three pensioners. We tried to formulate socially relevant problems, so that our results may contribute to understanding real-world issues. Moreover, we tried to avoid situations in which there is a well-defined legal solution to the distributional conflict, as this might influence strongly the answers of the respondents. In the discussion of the results, we will focus especially on the question of how respondents vary tolerance for inequality under variations of the characteristics of the claims problem and of the economic context. We organized the survey in two different countries, Belgium and Germany, in both cases using student samples. A priori one would not expect large differences in the attitudes of Belgian and German students: our results therefore offer a test of the robustness of the methodology.

The paper is structured as follows. In Sect. 2 we present several rules and introduce our conceptualization of tolerance for inequality. Section 3 discusses the setup of our questionnaire. In Sect. 4, the results of the questionnaire are presented and discussed. Section 5 concludes.

\section{Theoretical background}

An amount $E \in \mathbb{R}_{+}$has to be divided among a set $N=\{1,2, \ldots, n\}$ of individuals with claims adding up to more than $E$. Let $c_{i} \in \mathbb{R}_{+}$denote individual $i$ 's claim and $c=\left(c_{1}, c_{2}, \ldots, c_{n}\right)$ the claims vector. Claims are ordered so that $c_{1} \leq c_{2} \leq \cdots \leq c_{n}$. The total claim $\sum_{i \in N} c_{i}$ is assumed to be positive and is denoted by $C$. A claims problem is a pair $(c, E)$ with $C \geq E$. The set $\mathscr{C}$ collects all claims problems.

The literature on claims problems focuses on rules, which recommend for each claims problem a division between the individuals of the amount to divide. Formally, a rule is a function $R$ that associates with each claims problem $(c, E) \in \mathscr{C}$ a division $R(c, E)=\left(R_{1}(c, E), R_{2}(c, E), \ldots, R_{n}(c, E)\right) \in \mathbb{R}_{+}^{n}$. We refer to $R_{i}(c, E)$ as individual $i$ 's award and to $R(c, E)$ as the awards vector. The difference $c_{i}-R_{i}(c, E)$ is said to be individual $i$ 's loss. Awards vector are assumed to satisfy the following three conditions. (1) Efficiency: the sum of the awards equals the amount to divide. (2) Nonnegativity and claims boundedness: no individual receives an award smaller than zero or greater than her claim. (3) Order preservation: if individual $i$ 's claim is at least as great as individual $j$ 's claim, then $i$ 's award is at least as great as $j$ 's award, and $i$ 's loss is at least as great as $j$ 's loss. We accept these three conditions as part of the definition of a rule. They have real ethical content however, and are not necessarily innocuous when analysing opinions.

One of the objectives in the discussion of our questionnaire results will be to compare how well eight of the best-known rules for solving claims problems explain the choices of the respondents. The three oldest and most prominent rules are the proportional, constrained equal awards, and constrained equal losses rules.

The proportional rule already played a central role in Aristotle's theory of justice (Young 1994, pp. 64-65). The rule makes awards proportional to claims. 
Proportional rule, $\boldsymbol{P}$. For all $(c, E) \in \mathscr{C}$ and all $i \in N$, we have $P_{i}(c, E)=\frac{E}{C} c_{i}$.

The constrained equal awards and constrained equal losses rules both implement the idea of equality, be it in very different ways. Both rules were already discussed by Maimonides in the twelfth century (Aumann and Maschler 1985). The constrained equal awards rule equalizes awards under the constraint that no individual receives an award that exceeds her claim.

Constrained equal awards rule, $\boldsymbol{C E A}$. For all $(c, E) \in \mathscr{C}$ and all $i \in N$, we have $C E A_{i}(c, E)=\min \left\{c_{i}, \lambda\right\}$ where $\lambda \in \mathbb{R}_{+}$is chosen so as to achieve efficiency.

An awards vector for the constrained equal awards rule typically looks like $\left(c_{1}, c_{2}, \ldots, c_{k}, \lambda, \lambda, \ldots, \lambda\right)$.

The constrained equal losses rule equalizes losses under the constraint that no individual receives a negative award.

Constrained equal losses rule, $\boldsymbol{C E L}$. For all $(c, E) \in \mathscr{C}$ and all $i \in N$, we have $C E L_{i}(c, E)=\max \left\{0, c_{i}-\lambda\right\}$ where $\lambda \in \mathbb{R}$ is chosen so as to achieve efficiency.

An awards vector for the constrained equal losses rule typically looks like $(0,0, \ldots$, $\left.0, c_{k}-\lambda, c_{k+1}-\lambda, \ldots, c_{n}-\lambda\right)$.

Appendix A defines the five remaining rules: the Talmud (T), Piniles' (Pin), constrained egalitarian (CE), random arrival (RA), and minimal overlap (MO) rules. For a detailed discussion of the eight rules and their properties, we refer to the overview of the literature by Thomson (2003).

Several of these eight rules have been characterized in terms of formal axioms. But the rules also imply different attitudes to inequality, an aspect that may play an important role in the opinions of lay observers. It certainly is crucial in discussions about acquired rights in the real world. We shall pay special attention to this feature in discussing our results.

We make inequality comparisons using the Lorenz dominance relation, the cornerstone of the literature on inequality measurement. ${ }^{4}$ Let $x, y \in \mathbb{R}_{+}^{n}$ be two awards vectors proposed for the same claims problem-this implies that $x_{1} \leq x_{2} \leq \cdots \leq x_{n}$, $y_{1} \leq y_{2} \leq \cdots \leq y_{n}$, and $\sum_{i=1}^{n} x_{i}=\sum_{i=1}^{n} y_{i}$. We say that $x$ Lorenz dominates $y$ if $\sum_{i=1}^{k} x_{i} \geq \sum_{i=1}^{k} y_{i}$ for all $k=1,2, \ldots, n-1$, with at least one inequality holding strictly. Note that $x$ Lorenz dominates $y$ if and only if $x$ can be obtained from $y$ by transferring money from individuals with higher awards to individuals with lower awards. ${ }^{5}$ The vector $x$ is understood to be less unequal than the vector $y .{ }^{6}$

Consider Tables 3, 4, 5, 6, 7, 8, 9, 10 and 11, which present the solutions proposed by the various rules for the nine claims problems used in our questionnaire. As we

\footnotetext{
4 See Sen and Foster (1997) for an overview of this literature.

5 See, e.g., Sen and Foster (1997, pp. 54-55).

6 It does not follow that $x$ is preferable to $y$ as a solution to the given claims problem. Statements concerning Lorenz dominance are statements about inequality and not about ethical preferability. The particular economic context determines the extent to which inequality in claims ought to translate into inequality in awards. In Sect. 4.1, we will see that respondents indeed prefer different degrees of inequality in awards depending on the economic context.
} 


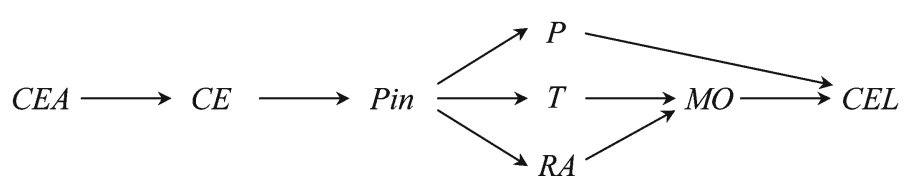

Fig. 1 Lorenz comparisons of eight rules. An arrow (or a sequence of arrows) from rule $R$ to rule $R^{\prime}$ indicates that, for each $(c, E) \in \mathscr{C}$, either $R(c, E)=R^{\prime}(c, E)$, or $R(c, E)$ Lorenz dominates $R^{\prime}(c, E)$. The absence of an arrow (or of a sequence of arrows) indicates the absence of such a general Lorenz relationship

move downward in a table, we move to awards vectors that are more unequal in the Lorenz sense. Indeed, for any two awards vectors, the upper one is obtained from the lower one by transferring money from individuals with higher awards to individuals with lower awards. The examples in Tables 3, 4, 5, 6, 7, 8, 9, 10 and 11 reveal some regularities. For instance, in all tables, the proportional division is at least as unequal as the Piniles' and constrained egalitarian divisions, and the minimal overlap division is at least as unequal as the Talmud and random arrival divisions. Some such inequality relationships between rules hold for every possible claims problem. Figure 1 presents these general Lorenz relationships. See Bosmans and Lauwers (2007) for proofs. ${ }^{7}$

The three prominent rules constitute benchmark cases with respect to equality preference, or progressivity. They imply a uniform attitude in terms of progressivity irrespective of the specific characteristics of the claims problem at hand. The constrained equal awards and constrained equal losses rules are at the two extremes. The former always selects the least unequal awards vector available for any rule, while the latter always selects the most unequal awards vector available for any rule. ${ }^{8}$ The proportional rule is neutral in terms of progressivity. Indeed, the literature on inequality measurement regards vectors which are proportional to one another as equally unequal. By consequence, the proportional rule preserves the inequality in the claims because it makes the awards vector proportional to the claims vector. ${ }^{9}$

In contrast to the three prominent rules, the behaviour of the other five rules with respect to progressivity is not so clear-cut. These rules do not behave in the same way with regard to progressivity for all claims problems. For instance, the constrained egalitarian rule is maximally progressive for the claims problem in Table 3, but neutral in terms of progressivity for the claims problem in Table 4. Tables 3, 4, 5, 6, 7, 8, 9, 10 and 11 yield similar examples for the remaining four rules.

\section{The setup of the questionnaire}

In the questionnaire, respondents were asked to state their preferred awards vector for nine different claims problems, which are presented in Table 1. Each of the nine

\footnotetext{
7 Related results are presented by Hougaard and Thorlund-Petersen (2001), Moreno-Ternero and Villar (2006), and Thomson (2008).

8 This result is well known in the literature. For a proof, see, e.g., Hougaard and Thorlund-Petersen (2001) or Bosmans and Lauwers (2007).

$9 \mathrm{Ju}$ and Moreno-Ternero (2008) consider inequality comparisons between the claims vector of a problem and the awards vector proposed as a solution to that problem.
} 
Table 1 The questions, all amounts in euros

\begin{tabular}{lll}
\hline Question 1 & $c=(1,500,2,000,2,500)$ & $E=4,500$ \\
Question 2 & $c=(1,500,2,000,2,500)$ & $E=3,000$ \\
Question 3 & $c=(1,500,2,000,2,500)$ & $E=1,500$ \\
Question 4 & $c=(1,000,2,000,3,000)$ & $E=4,500$ \\
Question 5 & $c=(1,000,2,000,3,000)$ & $E=3,000$ \\
Question 6 & $c=(1,000,2,000,3,000)$ & $E=1,500$ \\
Question 7 & $c=(500,2,000,3,500)$ & $E=4,500$ \\
Question 8 & $c=(500,2,000,3,500)$ & $E=3,000$ \\
Question 9 & $c=(500,2,000,3,500)$ & $E=1,500$ \\
\hline
\end{tabular}

claims problems is a combination of one of three possible claims vectors and one of three possible amounts to divide. The three possible claims vectors have the same sum of claims, but differ in terms of inequality (in the Lorenz sense). We mention the claims vectors in order of increasing inequality: $(1,500,2,000,2,500),(1,000,2,000$, $3,000)$, and $(500,2,000,3,500)$. The three possible amounts to divide, 4,500, 3,000, and 1,500, are greater than, equal to, and smaller than the sum of the half-claims, respectively. ${ }^{10}$ By using all nine combinations of these claims vectors and amounts to divide in our questionnaire, we obtain data for a wide variety of claims problems. The questionnaire design allows us to analyse the effect on responses of a change in the amount to divide for a given claims vector (questions 1, 2, and 3; questions 4, 5, and 6; questions 7, 8, and 9), as well as the effect of a change in claims inequality for a given amount to divide (questions 1, 4, and 7; questions 2, 5, and 8; questions 3, 6, and 9). For each of the nine questions, respondents were presented with a list of alternative awards vectors to choose from. These lists of awards vectors are given in Tables 3, $4,5,6,7,8,9,10$ and 11 . We emphasize that the information in the first two columns of these tables (pertaining to which rules are consistent with each of the awards vectors) was not presented to the respondents. To examine within-context consistency, i.e., the degree to which respondents use the same rule for different claims problems, the awards vectors selected by each of the rules defined in the previous section are included in the lists of alternatives for every question.

In order to tackle the question of between-context uniformity, i.e., the question of how the economic context in which the claims problems are presented affects responses, we consider two versions of the questionnaire with the same nine claims problems, but with different background stories. Each respondent gets only one version of the questionnaire. The questions in the "Firm" version are formulated as follows (here we consider question 1):

Persons $\mathrm{A}, \mathrm{B}$, and $\mathrm{C}$ own a firm together. $\mathrm{A}, \mathrm{B}$, and $\mathrm{C}$ contribute to the activities of the firm in different degrees, and for this reason they have agreed that their salaries differ. They receive monthly $€ 1,500, € 2,000$, and $€ 2,500$, respectively.

\footnotetext{
10 As is made clear in Appendix A, the position of the amount to divide relative to the sum of the half-claims is an important reference point in the definition of the Talmud, Piniles', and constrained egalitarian rules. It is also important in comparing the progressivity of the various rules: see Hougaard and Thorlund-Petersen (2001) and Bosmans and Lauwers (2007).
} 
Each of the three persons has also other sources of income. Due to an unexpected deterioration of the economic circumstances, the part of the revenue of the firm that can be used for salaries in a certain month amounts to only $€ 4,500$, not enough to compensate the three firm directors. What is in your view the most just distribution of the sum of $€ 4,500$ among persons $\mathrm{A}, \mathrm{B}$, and $\mathrm{C}$ ?

In the "Pensions" version, the questions were formulated as follows (we again consider question 1):

Persons A, B, and $\mathrm{C}$ go on retirement. On the basis of the contributions they have paid during their active career, they are entitled to a monthly pension of $€ 1,500$, $€ 2,000$, and $€ 2,500$, respectively. Due to the demographic ageing, these pension amounts can no longer be paid. The government only has $€ 4,500$ monthly to spend on the pensions of $\mathrm{A}, \mathrm{B}$, and $\mathrm{C}$. What is in your view the most just distribution of the sum of $€ 4,500$ among persons $\mathrm{A}, \mathrm{B}$, and $\mathrm{C}$ ?

The two versions of the questionnaire differ, explicitly or implicitly, in several respects. First, the status of the differences between the claims of the three individuals is different. In the Firm version, these differences are agreed upon by the three firm owners, while in the Pensions version they are explained by contributions in the past of the three pensioners and hence by wage differences during the active career. Therefore, in the Firm version respondents are likely to interpret the differences between claims to be caused more by desert and less by talent than in the Pensions version. Second, the two versions of the questionnaire differ with respect to the relation between the claims or awards and the ultimate outcomes relevant to the three individuals. In the Firm version it is specified that the individuals have also other sources of income. In the Pensions version on the other hand, it is likely that respondents view the pension amounts as very important, perhaps even the only, sources of income of the three individuals. Finally, the scope of the decision is different in the two versions of the questionnaire. Whereas in the Firm version awards pertain only to one monthly pay, in the Pensions version payments are implied to be determined by the decision for much longer.

Questions were presented in series of three: with the long introductions given above for the first of the three questions and shorter introductions for the second and third. After each series of three questions, respondents were encouraged to provide written comments on their choices. The questionnaire was anonymous. In order to test for order effects, we used several variants of the questionnaire with different orders of the questions and different orders of the alternatives. There were no significant differences between these alternative variants, and we therefore pooled all the data.

The questionnaire was conducted among the first year undergraduate economics and business students of the Catholic University of Leuven, Belgium, in May 2005, and among graduate economics and business students of the University of Osnabrück, Germany, in November 2005. None of the students had already been exposed to the theory of claims problems in their study programs. In the course of 1 week, the questionnaires were filled in by the students at the start of several exercise sessions. In each session, roughly half of the students participated in the Firm version of the 
Table 2 Sample sizes

\begin{tabular}{llll}
\hline & Belgium & Germany & All \\
\hline Firm & 123 & 153 & 276 \\
Pensions & 118 & 154 & 272 \\
\hline
\end{tabular}

questionnaire, and the other half in the Pensions version. The sample sizes are given in Table 2.

\section{Results}

\subsection{A first look}

Tables 3, 4, 5, 6, 7, 8, 9, 10 and 11 report the percentages of the respondents who chose each of the alternative awards vectors in questions 1-9. Results are given for the Belgian (B) and German (G) samples separately, as well as for the pooled sample

Table 3 Question 1, $c=(1,500,2,000,2,500)$ and $E=4,500$

\begin{tabular}{|c|c|c|c|c|c|c|c|c|c|}
\hline & \multirow[t]{2}{*}{ Rule(s) } & \multirow[t]{2}{*}{ Awards vector } & & \multicolumn{3}{|c|}{ Firm } & \multicolumn{3}{|c|}{ Pensions } \\
\hline & & & & B & G & All & B & G & All \\
\hline \multirow[t]{3}{*}{ Egalitarian } & CEA, CE & $(1,500,1,500,1,500)$ & & 4 & 5 & 4 & 4 & 2 & 3 \\
\hline & Pin & $(1,250,1,500,1,750)$ & & 12 & 14 & 13 & 21 & 16 & 18 \\
\hline & & & Total & 16 & 19 & 17 & 25 & 18 & 21 \\
\hline Neutral & $\mathrm{P}$ & $(1,125,1,500,1,875)$ & & 55 & 43 & 49 & 46 & 40 & 43 \\
\hline \multirow[t]{3}{*}{ Anti-egalitarian } & & $(1,050,1,500,1,950)$ & & 2 & 2 & 2 & 7 & 5 & 6 \\
\hline & CEL, T, RA, MO & $(1,000,1,500,2,000)$ & & 27 & 34 & 31 & 22 & 34 & 29 \\
\hline & & & Total & 29 & 36 & 33 & 29 & 39 & 35 \\
\hline
\end{tabular}

Table 4 Question 2, $c=(1,500,2,000,2,500)$ and $E=3,000$

\begin{tabular}{|c|c|c|c|c|c|c|c|c|c|}
\hline & \multirow[t]{2}{*}{ Rule(s) } & \multirow[t]{2}{*}{ Awards vector } & & \multicolumn{3}{|c|}{ Firm } & \multicolumn{3}{|c|}{ Pensions } \\
\hline & & & & $\mathrm{B}$ & G & All & $\mathrm{B}$ & G & All \\
\hline \multirow[t]{3}{*}{ Egalitarian } & CEA & $(1,000,1,000,1,000)$ & & 2 & 5 & 4 & 5 & 5 & 5 \\
\hline & & $(850,1,000,1,150)$ & & 14 & 7 & 10 & 22 & 13 & 17 \\
\hline & & & Total & 16 & 12 & 14 & 27 & 18 & 22 \\
\hline Neutral & P, T, CE, Pin, RA & $(750,1,000,1,250)$ & & 58 & 56 & 57 & 47 & 56 & 52 \\
\hline \multirow[t]{3}{*}{ Anti-egalitarian } & & $(650,1,000,1,350)$ & & 7 & 7 & 7 & 12 & 9 & 10 \\
\hline & CEL, MO & $(500,1,000,1,500)$ & & 20 & 24 & 22 & 14 & 16 & 15 \\
\hline & & & Total & 27 & 31 & 29 & 26 & 25 & 25 \\
\hline
\end{tabular}


Table 5 Question 3, $c=(1,500,2,000,2,500)$ and $E=1,500$

\begin{tabular}{|c|c|c|c|c|c|c|c|c|c|}
\hline & \multirow[t]{2}{*}{ Rule(s) } & \multirow[t]{2}{*}{ Awards vector } & & \multicolumn{3}{|c|}{ Firm } & \multicolumn{3}{|c|}{ Pensions } \\
\hline & & & & B & G & All & $\mathrm{B}$ & G & All \\
\hline \multirow[t]{3}{*}{ Egalitarian } & CEA, T, CE, Pin, RA, MO & $(500,500,500)$ & & 9 & 5 & 7 & 11 & 16 & 14 \\
\hline & & $(450,500,550)$ & & 9 & 9 & 9 & 24 & 14 & 18 \\
\hline & & & Total & 18 & 14 & 16 & 36 & 30 & 32 \\
\hline Neutral & $\mathrm{P}$ & $(375,500,625)$ & & 59 & 50 & 54 & 44 & 42 & 43 \\
\hline \multirow[t]{3}{*}{ Anti-egalitarian } & & $(250,500,750)$ & & 21 & 27 & 24 & 16 & 24 & 20 \\
\hline & CEL & $(0,500,1,000)$ & & 3 & 7 & 5 & 3 & 3 & 3 \\
\hline & & & Total & 24 & 34 & 29 & 19 & 27 & 23 \\
\hline
\end{tabular}

Table 6 Question 4, $c=(1,000,2,000,3,000)$ and $E=4,500$

\begin{tabular}{|c|c|c|c|c|c|c|c|c|c|}
\hline & \multirow[t]{2}{*}{ Rule(s) } & \multirow[t]{2}{*}{ Awards vector } & & \multicolumn{3}{|c|}{ Firm } & \multicolumn{3}{|c|}{ Pensions } \\
\hline & & & & B & G & All & $\mathrm{B}$ & G & All \\
\hline \multirow[t]{3}{*}{ Egalitarian } & CEA, CE & $(1,000,1,750,1,750)$ & & 1 & 2 & 2 & 0 & 1 & 0 \\
\hline & Pin & $(1,000,1,500,2,000)$ & & 11 & 13 & 12 & 17 & 16 & 17 \\
\hline & & & Total & 12 & 15 & 14 & 17 & 17 & 17 \\
\hline Neutral & $\mathrm{P}$ & $(750,1,500,2,250)$ & & 73 & 58 & 65 & 64 & 64 & 64 \\
\hline \multirow[t]{3}{*}{ Anti-egalitarian } & RA & $(666,1,416,2,416)$ & & 4 & 4 & 4 & 5 & 6 & 6 \\
\hline & CEL, T, MO & $(500,1,500,2,500)$ & & 11 & 20 & 16 & 14 & 12 & 13 \\
\hline & & & Total & 15 & 24 & 20 & 19 & 18 & 19 \\
\hline
\end{tabular}

Table 7 Question 5, $c=(1,000,2,000,3,000)$ and $E=3,000$

\begin{tabular}{|c|c|c|c|c|c|c|c|c|c|}
\hline & \multirow[t]{2}{*}{ Rule(s) } & \multirow[t]{2}{*}{ Awards vector } & & \multicolumn{3}{|c|}{ Firm } & \multicolumn{3}{|c|}{ Pensions } \\
\hline & & & & B & G & All & B & G & All \\
\hline \multirow[t]{3}{*}{ Egalitarian } & CEA & $(1,000,1,000,1,000)$ & & 2 & 1 & 1 & 3 & 3 & 3 \\
\hline & & $(700,1,000,1,300)$ & & 14 & 10 & 12 & 24 & 19 & 21 \\
\hline & & & Total & 16 & 11 & 13 & 27 & 22 & 24 \\
\hline Neutral & P, T, CE, Pin, RA & $(500,1,000,1,500)$ & & 73 & 72 & 73 & 61 & 69 & 66 \\
\hline \multirow[t]{3}{*}{ Anti-egalitarian } & $\mathrm{MO}$ & $(333,833,1,833)$ & & 9 & 8 & 8 & 9 & 6 & 7 \\
\hline & CEL & $(0,1,000,2,000)$ & & 2 & 6 & 4 & 3 & 1 & 2 \\
\hline & & & Total & 11 & 14 & 12 & 12 & 7 & 9 \\
\hline
\end{tabular}

(All). Recall that the awards vectors appear in sequence of increasing inequality (in the Lorenz sense). We have distinguished three sets of alternatives in the tables. First, the neutral awards vector is the one consistent with the proportional rule. Second, the 
Table 8 Question 6, $c=(1,000,2,000,3,000)$ and $E=1,500$

\begin{tabular}{|c|c|c|c|c|c|c|c|c|c|}
\hline & \multirow[t]{2}{*}{ Rule(s) } & \multirow[t]{2}{*}{ Awards vector } & & \multicolumn{3}{|c|}{ Firm } & \multicolumn{3}{|c|}{ Pensions } \\
\hline & & & & B & G & All & B & G & All \\
\hline \multirow[t]{3}{*}{ Egalitarian } & CEA, T, CE, Pin & $(500,500,500)$ & & 11 & 5 & 8 & 14 & 19 & 17 \\
\hline & $\mathrm{MO}, \mathrm{RA}$ & $(333,583,583)$ & & 4 & 2 & 3 & 17 & 9 & 12 \\
\hline & & & Total & 15 & 7 & 11 & 31 & 28 & 29 \\
\hline Neutral & $\mathrm{P}$ & $(250,500,750)$ & & 70 & 70 & 70 & 58 & 53 & 55 \\
\hline \multirow[t]{3}{*}{ Anti-egalitarian } & & $(150,500,850)$ & & 12 & 14 & 13 & 8 & 11 & 9 \\
\hline & CEL & $(0,250,1,250)$ & & 3 & 5 & 4 & 2 & 2 & 2 \\
\hline & & & Total & 15 & 19 & 17 & 10 & 13 & 11 \\
\hline
\end{tabular}

Table 9 Question 7, $c=(500,2,000,3,500)$ and $E=4,500$

\begin{tabular}{|c|c|c|c|c|c|c|c|c|c|}
\hline & \multirow[t]{2}{*}{ Rule(s) } & \multirow[t]{2}{*}{ Awards vector } & & \multicolumn{3}{|c|}{ Firm } & \multicolumn{3}{|c|}{ Pensions } \\
\hline & & & & $\mathrm{B}$ & G & All & $\mathrm{B}$ & G & All \\
\hline \multirow[t]{5}{*}{ Egalitarian } & CEA, CE & $(500,2,000,2,000)$ & & 3 & 3 & 3 & 5 & 4 & 4 \\
\hline & Pin & $(500,1,625,2,375)$ & & 10 & 7 & 8 & 18 & 25 & 22 \\
\hline & & $(450,1,600,2,450)$ & & 2 & 4 & 3 & 12 & 10 & 11 \\
\hline & & $(400,1,500,2,600)$ & & 12 & 11 & 11 & 13 & 9 & 10 \\
\hline & & & Total & 27 & 25 & 25 & 48 & 48 & 47 \\
\hline Neutral & $\mathrm{P}$ & $(375,1,500,2,625)$ & & 48 & 47 & 48 & 34 & 29 & 31 \\
\hline \multirow[t]{5}{*}{ Anti-egalitarian } & RA & $(333,1,333,2,833)$ & & 3 & 6 & 5 & 7 & 6 & 6 \\
\hline & $\mathrm{T}$ & $(250,1,375,2,875)$ & & 12 & 9 & 10 & 6 & 7 & 6 \\
\hline & MO & $(166,1,416,2,916)$ & & 7 & 5 & 6 & 2 & 5 & 3 \\
\hline & CEL & $(0,1,500,3,000)$ & & 4 & 5 & 4 & 2 & 3 & 2 \\
\hline & & & Total & 26 & 25 & 25 & 17 & 21 & 17 \\
\hline
\end{tabular}

awards vectors that Lorenz dominate the neutral solution are referred to as egalitarian. Third, the anti-egalitarian awards vectors are the ones that are Lorenz dominated by the neutral solution. The tables also report which rules are consistent with each of the alternative awards vectors.

The results are very similar for Belgium and Germany. The $\chi^{2}$ tests in the first nine rows of Table 12 test, for each question separately, the null hypothesis that the population proportions for the categories egalitarian, neutral, and anti-egalitarian, respectively, are equal for Belgium and Germany. The test in the last row does the same for the complete set of questions, i.e., for $27(3 \times 9)$ categories. The evidence clearly supports the null hypothesis. Therefore, we will discuss the pooled data in this subsection. Given the small differences in the characteristics of the Belgian and German samples, significant differences between the results would have been rather worrying. 
Table 10 Question 8, $c=(500,2,000,3,500)$ and $E=3,000$

\begin{tabular}{|c|c|c|c|c|c|c|c|c|c|}
\hline & \multirow[t]{2}{*}{ Rule(s) } & \multirow{2}{*}{\multicolumn{2}{|c|}{ Awards vector }} & \multicolumn{3}{|c|}{ Firm } & \multicolumn{3}{|c|}{ Pensions } \\
\hline & & & & B & $\mathrm{G}$ & All & B & G & All \\
\hline \multirow[t]{3}{*}{ Egalitarian } & CEA & $(500,1,250,1,250)$ & & 6 & 4 & 5 & 17 & 12 & 14 \\
\hline & & $(350,1,100,1,550)$ & & 13 & 8 & 10 & 30 & 23 & 26 \\
\hline & & & Total & 19 & 12 & 15 & 47 & 35 & 40 \\
\hline Neutral & P, T, CE, Pin, RA & $(250,1,000,1,750)$ & & 67 & 72 & 70 & 44 & 43 & 44 \\
\hline \multirow[t]{3}{*}{ Anti-egalitarian } & MO & $(166,916,1,916)$ & & 9 & 7 & 8 & 4 & 7 & 6 \\
\hline & CEL & $(0,750,2,250)$ & & 3 & 5 & 4 & 2 & 1 & 2 \\
\hline & & & Total & 12 & 12 & 12 & 6 & 8 & 8 \\
\hline
\end{tabular}

Table 11 Question $9, c=(500,2,000,3,500)$ and $E=1,500$

\begin{tabular}{|c|c|c|c|c|c|c|c|c|c|}
\hline & \multirow[t]{2}{*}{ Rule(s) } & \multirow[t]{2}{*}{ Awards vector } & & \multicolumn{3}{|c|}{ Firm } & \multicolumn{3}{|c|}{ Pensions } \\
\hline & & & & B & G & All & B & G & All \\
\hline \multirow[t]{4}{*}{ Egalitarian } & CEA & $(500,500,500)$ & & 4 & 3 & 4 & 17 & 17 & 17 \\
\hline & T, CE, Pin & $(250,625,625)$ & & 6 & 3 & 4 & 16 & 8 & 12 \\
\hline & MO, RA & $(166,666,666)$ & & 5 & 0 & 2 & 3 & 3 & 3 \\
\hline & & & Total & 15 & 6 & 10 & 36 & 28 & 32 \\
\hline Neutral & $\mathrm{P}$ & $(125,500,875)$ & & 62 & 64 & 63 & 46 & 42 & 43 \\
\hline \multirow[t]{4}{*}{ Anti-egalitarian } & & $(100,450,950)$ & & 9 & 12 & 11 & 6 & 9 & 7 \\
\hline & & $(50,450,1,000)$ & & 8 & 9 & 9 & 3 & 9 & 6 \\
\hline & CEL & $(0,0,1,500)$ & & 4 & 4 & 4 & 3 & 3 & 3 \\
\hline & & & Total & 21 & 25 & 24 & 12 & 21 & 16 \\
\hline
\end{tabular}

The support for the null hypothesis is a reassuring indication that our questionnaire method leads to robust findings.

We first focus on the question of between-context uniformity, i.e., on the differences between the results obtained with the two versions of the questionnaire. Overall, responses are less egalitarian in the Firm version than in the Pensions version. In all nine questions, the percentage of the respondents that chose egalitarian awards vectors is lower in the Firm version than in the Pensions version, and in eight out of nine questions the percentage that chose anti-egalitarian awards vectors is higher in the Firm version than in the Pensions version. The first nine rows of Table 13 test, for each question separately, the null hypothesis that the population proportions for the categories egalitarian, neutral, and anti-egalitarian, respectively, are equal for the two questionnaire versions, and the last row does the same for the complete set of questions. Table 13 confirms that responses are significantly different for the two versions. The evidence that respondents chose less egalitarian alternatives in the Firm 
Table 12 Homogeneity of Belgian and German results, $p$ values for $\chi^{2}$ tests

\begin{tabular}{lll}
\hline Question & Firm & Pensions \\
\hline 1 & 0.187 & 0.116 \\
2 & 0.463 & 0.150 \\
3 & 0.113 & 0.407 \\
4 & 0.064 & 0.981 \\
5 & 0.464 & 0.267 \\
6 & 0.148 & 0.637 \\
7 & 0.995 & 0.609 \\
8 & 0.294 & 0.432 \\
9 & 0.061 & 0.076 \\
All questions & 0.350 & 0.726 \\
\hline
\end{tabular}

Table 13 Homogeneity of firm and pensions versions, $p$ values for $\chi^{2}$ tests

\begin{tabular}{llll}
\hline Question & Belgium & Germany & All \\
\hline 1 & 0.172 & 0.810 & 0.308 \\
2 & 0.095 & 0.252 & 0.047 \\
3 & 0.010 & 0.003 & 0.000 \\
4 & 0.287 & 0.304 & 0.417 \\
5 & 0.074 & 0.011 & 0.002 \\
6 & 0.007 & 0.000 & 0.000 \\
7 & 0.002 & 0.000 & 0.000 \\
8 & 0.000 & 0.000 & 0.000 \\
9 & 0.000 & 0.000 & 0.000 \\
All questions & 0.000 & 0.000 & 0.000 \\
\hline
\end{tabular}

version than in the Pensions version is particularly strong in the case of questions 3, 6 , 7,8 , and 9 . Note that in each of these questions the majority of the alternative award vectors feature incomes lower than $€ 500$, an amount close to the minimally guaranteed income in Belgium and Germany. The fact that respondents in the Pensions version are especially egalitarian in these cases, suggests that they may have some concern for a minimum level of income being respected-in fact, this concern was expressed explicitly by several respondents in the comments box of the questionnaire. Put differently, for low awards, considerations with respect to needs appear to override considerations with respect to claims. It is interesting to note that the evidence suggests that the reason why respondents choose more egalitarian alternatives in the Pensions version is not because they favour equality in itself, but rather because they want to make sure individuals get a sufficient amount of income. We will return to the interpretation of these results in Sect. 4.4.

The aggregate data given in Tables $3,4,5,6,7,8,9,10$ and 11 are not suitable for examining within-context consistency, i.e., for evaluating the degree to which rules are successful in describing the choices of the respondents. It is inherent in the definition of a rule that it proposes an awards vector for every claims problem. Hence, to evaluate the acceptance of a given rule, we need to look at the entire response patterns 
of individual respondents, not just at overall mean responses. However, one first impression on the basis of the aggregate data is worth mentioning. The awards vectors consistent with the proportional rule perform very well in explaining responses: they are convincingly most popular in every question. Although this is true for both versions of the questionnaire, it is even more outspoken in the Firm version than in the Pensions version. Note that, both for the Firm version and for the Pensions version, the proportional rule is especially popular in questions 4,5 , and 6 where the claims vector is $(1,000,2,000,3,000)$. It is hard to find an economic explanation for this observation-perhaps it is simply due to the fact that, for the given claims vector, the awards vectors of the proportional rule are particularly easy to calculate.

In the next subsection, we will provide a more robust analysis based on individuallevel data to compare the empirical performance of the various rules. Before moving on, however, we discuss two basic intuitions of the respondents that are revealed in the aggregate data for both versions of the questionnaire: concerns for strict order preservation and nonzero awards. Both of these concerns were also stated explicitly in comments by several respondents.

Respondents in both questionnaire versions seem to want the order in claims to be preserved strictly in awards. Alternatives in which individuals with different claims get equal awards only appear in the sets of egalitarian awards vectors of the questions. For all questions in which alternatives are available in the set of egalitarian awards vectors that respect strict order preservation (this is the case in all questions except 6 and 9), the awards vector that violates strict order preservation is least popular among the egalitarian awards vectors for both questionnaire versions. Since the constrained equal awards rule never respects strict order preservation for the claims problems in our questionnaire, its awards vectors perform rather badly in describing respondents' choices.

There is a reluctance among respondents in both questionnaire versions to give an individual a zero award. Awards vectors in which an individual gets a zero award only appear as the least egalitarian alternative in the set of anti-egalitarian awards vectors of the questions. In all questions in which such an alternative is present (all questions except 1,2, and 4), it is least popular among the anti-egalitarian awards vectors for both versions of the questionnaire. This is particularly relevant to explain the limited success of the constrained equal losses rule, which always selects the awards vector with zero awards in these cases. At the same time, in the questions in which the constrained equal losses rule gives everyone strictly more than zero (questions 1, 2, and 4 ), its awards vectors are most popular in the set of anti-egalitarian solutions.

\subsection{A comparison of rules}

Strictly speaking, a respondent is consistent with a rule only if she chooses the awards vectors implied by the rule in all questions. Due to the relatively high number of questions in the questionnaire, this test is rather demanding. Nevertheless, as Table 14 shows, substantial numbers of respondents were consistent with the proportional rule in all nine questions for both questionnaire versions. Given this good performance, it is not surprising that respondents often mentioned in their comments that they were 
Table 14 Percentages of consistency with rules

\begin{tabular}{|c|c|c|c|c|c|c|}
\hline \multirow[t]{2}{*}{ Rule } & \multicolumn{3}{|c|}{ Firm } & \multicolumn{3}{|c|}{ Pensions } \\
\hline & B & G & All & B & G & All \\
\hline $\mathrm{P}$ & 38 & 33 & 36 & 20 & 19 & 19 \\
\hline CEA & 0 & 0 & 0 & 0 & 0 & 0 \\
\hline CEL & 2 & 3 & 2 & 2 & 1 & 1 \\
\hline $\mathrm{T}$ & 0 & 0 & 0 & 0 & 0 & 0 \\
\hline Pin & 0 & 0 & 0 & 0 & 0 & 0 \\
\hline $\mathrm{CE}$ & 0 & 0 & 0 & 0 & 0 & 0 \\
\hline RA & 0 & 0 & 0 & 0 & 0 & 0 \\
\hline MO & 0 & 0 & 0 & 0 & 0 & 0 \\
\hline
\end{tabular}

applying a proportional procedure throughout the questionnaire. The only other rule that respondents have chosen consistently with in all nine questions is the constrained equal losses rule: however, this is the case only for very low numbers of respondents in each of the two versions of the questionnaire. Our finding concerning the dominating position of the proportional rule is in line with the questionnaire results of Béhue (2003), Gächter and Riedl (2006), and Herrero et al. (2006).

Yet, Table 14 also shows that the largest fraction of the respondents (about $60 \%$ in the Firm version and about $80 \%$ in the Pensions version) give responses that are not fully consistent with any of the rules that have been proposed in the theoretical literature. In some cases, this may be due to calculation or rounding errors. It is more likely, however, that the ethical intuitions of the respondents vary with the characteristics of the problem in a way which is not captured by any of the rules. This will be analysed in more detail in the next subsection. Still, as a first intuitive approach, it is informative to see how well the answers of the respondents can be approximated by the different rules. One possibility to measure this is to use the following concept of "distance". Let $\left(c^{\ell}, E^{\ell}\right)$ be the claims problem used in question $\ell=1,2, \ldots, 9$ and denote the awards vector chosen by respondent $k$ in question $\ell$ by $A^{k}\left(c^{\ell}, E^{\ell}\right)$. We define the distance between the set of awards vectors chosen by $k$ and the set of awards vectors for rule $R$ as $\sum_{\ell=1}^{9} \sum_{i=1}^{3}\left|A_{i}^{k}\left(c^{\ell}, E^{\ell}\right)-R_{i}\left(c^{\ell}, E^{\ell}\right)\right|$, i.e., as the total money amount that respondent $k$ deviates from what is prescribed by rule $R .{ }^{11}$ If a respondent chooses consistently according to rule $R$, then the distance for $R$ is zero. More generally, the lower the distance, the better the performance of the rule in describing the choices of the given respondent. For each individual, we then consider her response behaviour to be "closest" to a rule if the corresponding distance is smallest. Note that these distances unavoidably depend on the award vectors that we offered as alternatives to the respondents. However, this bias is limited since the alternative award vectors for each question are quite evenly spaced.

Table 15 presents, for each rule, the percentages of the respondents for whom the rule is ranked first, i.e., for whom the distance to the given rule is lower than that to each

\footnotetext{
11 Gächter and Riedl (2006) consider the differences between observed and theoretical awards vectors for a two-claimant problem. Our distance measure is a natural generalization of their approach to response patterns over several questions and to problems with more than two claimants.
} 
Table 15 Percentages of lowest distances to award vectors of rules

\begin{tabular}{|c|c|c|c|c|c|c|c|}
\hline & \multirow[t]{2}{*}{ Rule } & \multicolumn{3}{|c|}{ Firm } & \multicolumn{3}{|c|}{ Pensions } \\
\hline & & B & G & All & B & G & All \\
\hline \multirow[t]{3}{*}{ Egalitarian } & CEA & 2 & 1 & 2 & 4 & 3 & 4 \\
\hline & $\mathrm{CE}$ & 1 & 1 & 1 & 0 & 0 & 0 \\
\hline & Pin & 6 & 5 & 5 & 23 & 16 & 19 \\
\hline \multirow[t]{4}{*}{ Neutral or ambiguous } & $\mathrm{P}$ & 75 & 68 & 71 & 58 & 55 & 56 \\
\hline & $\mathrm{T}$ & 2 & 5 & 4 & 2 & 2 & 2 \\
\hline & RA & 6 & 12 & 9 & 5 & 20 & 14 \\
\hline & MO & 6 & 5 & 5 & 6 & 3 & 4 \\
\hline Anti-egalitarian & CEL & 2 & 5 & 4 & 3 & 1 & 2 \\
\hline
\end{tabular}

other rule. The categories are defined in accordance with Fig. 1. As before, the category neutral refers to the proportional rule. The category egalitarian includes the rules that always select award vectors that are at most as unequal as the proportional division. The category anti-egalitarian includes the rules that always select award vectors that are at least as unequal as the proportional division. A rule is categorized as ambiguous if it does not belong to any of the other three categories. For the Firm version, the proportional rule clearly performs best. Of the other rules, the random arrival rule stands out somewhat in the German sample, but not in the Belgian sample. For the Pensions version, the proportional rule also comes out first, but less overwhelmingly so: Piniles' rule and, in the German sample, the random arrival rule also perform well. It is remarkable that Piniles' rule and the random arrival rule outperform the prominent constrained equal awards and constrained equal losses rules. As suggested before, this may be linked to the concern for strict order preservation and to the reluctance to award zero amounts. Table 15 also confirms the conclusion with respect to the differences between the two questionnaire versions that was stated in the previous subsection: egalitarian rules do better in the Pensions version.

\subsection{Variations in degree of egalitarianism}

In the previous subsection, we studied the question of within-context consistency, i.e., whether respondents use the same rule for each claims problem. Here, we consider a similar question but in terms of progressivity. We examine whether respondents take, for each claims problem, the same position with respect to progressivity, or whether they vary their position in a straightforward manner depending on the characteristics of the claims problem at hand. Specifically, we analyse whether there is a meaningful pattern to be found under two basic variations of the claims problem: (a) a decrease of the amount to divide while the claims remain the same, and (b) an increase in the inequality of the claims vector while the amount to divide remains the same.

In Table 16, the response patterns over the combinations of questions relevant for question (a) are summarized (in percentages). The category same covers the response patterns consistent with the proportional rule, the constrained equal awards rule, or 
Table 16 Evolution of progressivity as the amount to divide decreases

\begin{tabular}{|c|c|c|c|c|c|c|c|c|}
\hline \multirow[t]{2}{*}{ Questions } & \multirow[t]{2}{*}{ Context } & \multicolumn{3}{|c|}{ Same } & \multirow[t]{2}{*}{ Decrease } & \multirow[t]{2}{*}{ Increase } & \multirow[t]{2}{*}{ Decrease-increase } & \multirow[t]{2}{*}{ Increase-decrease } \\
\hline & & $\mathrm{P}$ & CEA & CEL & & & & \\
\hline \multicolumn{9}{|l|}{ Belgium } \\
\hline \multirow[t]{2}{*}{$1,2,3$} & Firm & 45 & 2 & 2 & $3(0.998)$ & $22(0.000)$ & $9(0.923)$ & $4(1.000)$ \\
\hline & Pensions & 29 & 2 & 2 & $9(0.872)$ & $26(0.000)$ & $6(1.000)$ & $3(1.000)$ \\
\hline \multirow[t]{2}{*}{$4,5,6$} & Firm & 55 & 0 & 2 & $8(0.471)$ & $16(0.000)$ & $2(1.000)$ & $7(0.962)$ \\
\hline & Pensions & 39 & 0 & 2 & $6(0.978)$ & $21(0.000)$ & $2(1.000)$ & $5(1.000)$ \\
\hline \multirow[t]{2}{*}{$7,8,9$} & Firm & 43 & 1 & 2 & $11(0.106)$ & $10(0.179)$ & $2(1.000)$ & $10(0.952)$ \\
\hline & Pensions & 25 & 3 & 2 & $7(0.881)$ & $15(0.025)$ & $4(1.000)$ & $11(0.990)$ \\
\hline \multicolumn{9}{|l|}{ Germany } \\
\hline \multirow[t]{2}{*}{$1,2,3$} & Firm & 37 & 2 & 4 & $7(0.929)$ & $25(0.000)$ & $5(1.000)$ & 7 (0.999) \\
\hline & Pensions & 26 & 1 & 3 & $7(0.996)$ & $34(0.000)$ & $7(1.000)$ & $6(1.000)$ \\
\hline \multirow[t]{2}{*}{$4,5,6$} & Firm & 48 & 0 & 5 & $10(0.289)$ & $14(0.012)$ & $1(1.000)$ & $5(1.000)$ \\
\hline & Pensions & 36 & 0 & 1 & $8(0.890)$ & $24(0.000)$ & $3(1.000)$ & 7 (0.999) \\
\hline \multirow[t]{2}{*}{$7,8,9$} & Firm & 40 & 0 & 3 & $17(0.000)$ & $11(0.114)$ & $2(1.000)$ & $9(0.989)$ \\
\hline & Pensions & 20 & 1 & 1 & $10(0.546)$ & $15(0.047)$ & $1(1.000)$ & $10(1.000)$ \\
\hline
\end{tabular}

the constrained equal losses rule, i.e., the patterns in which the degree of progressivity remains unchanged. The other four categories-decrease, increase, decreaseincrease, and increase-decrease-describe simple variations in progressivity, and are also defined using the three prominent rules as benchmark cases. To give an example: a response pattern over questions 1,2 , and 3 which is consistent with the constrained equal awards rule in question 1, consistent with the proportional rule in question 2 and consistent with the constrained equal losses rule in question 3, would be categorized under decrease. A complete description of the response patterns belonging to each of the categories is given in Appendix B. The conclusions of this subsection are qualitatively the same for the Belgian and German samples: because, as a consequence, the results for the pooled sample do not provide additional insights, we do not give these in the tables.

The category same performs best empirically, a result that can be ascribed to the popularity of the proportional rule. It is more interesting to examine how well the various other categories perform in describing the choices of those respondents not consistent with the same category. Therefore, Table 16 provides $p$ values for the null hypothesis that the population proportion for each of the given categories is equal to what it would be if choices of respondents not consistent with the same category were completely random. ${ }^{12}$ We find that, for both versions of the questionnaire, the category increase, describing an increase in progressivity as the amount to divide decreases, performs well empirically, whereas all other categories fail. The popularity of the increase category is consistent with the observation made in Sect. 4.1 that

\footnotetext{
12 The $p$ values are for the one sided exact test based on the binomial distribution.
} 
Table 17 Evolution of progressivity as claims inequality increases

\begin{tabular}{|c|c|c|c|c|c|c|c|c|}
\hline \multirow[t]{2}{*}{ Questions } & \multirow[t]{2}{*}{ Context } & \multicolumn{3}{|c|}{ Same } & \multirow[t]{2}{*}{ Decrease } & \multirow[t]{2}{*}{ Increase } & \multirow[t]{2}{*}{ Decrease-increase } & \multirow[t]{2}{*}{ Increase-decrease } \\
\hline & & $\mathrm{P}$ & CEA & CEL & & & & \\
\hline \multicolumn{9}{|l|}{ Belgium } \\
\hline \multirow[t]{2}{*}{$1,4,7$} & Firm & 42 & 0 & 2 & $11(0.242)$ & $22(0.000)$ & $8(0.988)$ & $7(0.998)$ \\
\hline & Pensions & 21 & 0 & 2 & $8(0.908)$ & $34(0.000)$ & $13(0.983)$ & $3(1.000)$ \\
\hline \multirow[t]{2}{*}{$2,5,8$} & Firm & 49 & 2 & 2 & $3(0.996)$ & $17(0.001)$ & $2(1.000)$ & $7(0.966)$ \\
\hline & Pensions & 30 & 1 & 2 & $3(1.000)$ & $26(0.000)$ & $9(0.994)$ & $2(1.000)$ \\
\hline \multirow[t]{2}{*}{$3,6,9$} & Firm & 48 & 4 & 2 & $11(0.106)$ & $8(0.414)$ & $2(1.000)$ & $7(0.957)$ \\
\hline & Pensions & 34 & 8 & 2 & $5(0.972)$ & $18(0.002)$ & $5(1.000)$ & $3(1.000)$ \\
\hline \multicolumn{9}{|l|}{ Germany } \\
\hline \multirow[t]{2}{*}{$1,4,7$} & Firm & 35 & 1 & 4 & $4(0.997)$ & $26(0.000)$ & $6(1.000)$ & $7(1.000)$ \\
\hline & Pensions & 21 & 0 & 1 & $5(0.998)$ & $32(0.000)$ & $10(0.999)$ & $7(1.000)$ \\
\hline \multirow[t]{2}{*}{$2,5,8$} & Firm & 48 & 0 & 5 & $7(0.856)$ & $20(0.000)$ & $2(1.000)$ & $4(1.000)$ \\
\hline & Pensions & 30 & 1 & 1 & $3(1.000)$ & $25(0.000)$ & $7(1.000)$ & $6(1.000)$ \\
\hline \multirow[t]{2}{*}{$3,6,9$} & Firm & 42 & 2 & 4 & $9(0.512)$ & $11(0.125)$ & $3(1.000)$ & $9(0.946)$ \\
\hline & Pensions & 26 & 12 & 2 & $10(0.428)$ & $14(0.037)$ & $1(1.000)$ & $8(0.996)$ \\
\hline
\end{tabular}

respondents seem to attribute importance to minimal income needs. What is interesting is that this pattern appears to be present not only for the Pensions version of the questionnaire, but also for the Firm version, albeit in a somewhat weaker form.

Table 17 presents similar results as Table 16 but for question (b), i.e., for an increase in the inequality of the claims vector while keeping the amount to divide constant. As before, the same consistent patterns perform very well. The question that again arises is how the other categories perform in describing the choices of the respondents who are not consistent with this category. The table shows that, for both the Firm version and the Pensions version, the increase category, describing an increase in progressivity as claims inequality increases, performs very well empirically, whereas all other categories fail. ${ }^{13}$ A similar pattern was found by Gächter and Riedl (2006) on the basis of results for two questions. The good performance of the increase category may again be seen as an indication of the importance of minimal income needs: as claims inequality increases, the claim of the individual with the lowest claim decreases, so that an increase in progressivity is required in order to ensure a minimal amount for the individual in question.

The pattern of increasing progressivity in the cases of decreasing amount to divide or increasing claims inequality is striking. It seems worthwhile to work out the theoretical consequences of this idea.

\footnotetext{
13 Note that the increase category is less popular for the combination of questions 3,6 , and 9 . In the Pensions version, however, the popularity of the constrained equal awards rule (in the same category) for this combination is remarkable. Since the constrained equal awards rule is the most progressive rule possible, its good performance is to the disadvantage of the increase category.
} 


\subsection{Acquired rights and claims problems in the real world}

It is of course impossible to draw strong policy conclusions from the answers on highly stylized questions that abstract completely from possibly crucial institutional features. In this respect our results are complementary to those derived from more policy oriented questionnaires, as exemplified in Boeri et al. (2001, 2002). Contrary to the simplified problems in our setting, that certainly put the respondents in a kind of straightjacket, broader opinion surveys have the advantage of integrating the ethical issues in a more realistic background. To give an example, for the pensions problem it is worthwhile, perhaps even necessary, to compare the attitudes towards decreasing benefits (on which we focus in our stylized questions) with the attitudes towards increasing contributions or delaying retirement. On the other hand, introducing such a richer and more realistic institutional background makes it more difficult to focus in detail on more complicated specific issues. The precise structure of desired benefit (or earnings) reductions can only be made operational through a series of rather abstract questions and it is not obvious how to integrate such abstract questions in a broader survey. More importantly, real-world opinions reflect a mixture of self-interest and fairness considerations and the relative importance of both components may be different for different respondents. This makes it extremely difficult to derive from these opinions a specific view on fairness ideas as such. Yet from a theoretical point of view, distinguishing self-interest and fairness considerations is certainly useful to get a better understanding of the reasons for differences and similarities in individual behaviour.

Let us now, with these caveats in mind, cautiously formulate some general conclusions on real-world issues that we can draw from our questionnaire results. In the first place, our results confirm that feelings about being treated in a fair way may play a crucial role in the psychological acceptability of different distributions. One may indeed hypothesize that both the requirement that the order in claims is preserved strictly in the awards and the requirement that no individual should get a zero award, express deep psychological feelings about a minimum level of respect for acquired rights. Note that in our setting these concerns were expressed (implicitly) by observers who are not themselves directly involved in the distributional conflict.

In the second place, the dominating position of the proportional rule is striking and is certainly in line with everyday practice. It turns out, however, that the popularity of more progressive rules increases if the distribution problem gets more "difficult", in that either the amount to divide decreases or the inequality in the initial claims increases. In general, this suggests that an overall perspective on inequality plays a role in the evaluation of different solutions. More particularly, our findings may express a specific concern for the weakest groups, even in the firm setting where the claims are closely linked to productive contributions and have been agreed upon by the parties concerned.

In the third place, mainly in the pensions problem, we recover the popularity of the idea of a "minimum floor" in the distribution. This idea is described by Elster (1992) as an integral part of the commonsense conception of justice. It came also out strongly in the experiments of Frohlich and Oppenheimer (1992). At the same time, however, even in the pensions case responses were dominated by the proportional 
rule. Our respondents overall do not express a strongly egalitarian view on pensions. Perhaps we should not exaggerate the importance of this finding. It may be caused by the general setting of the questionnaire, by which the attention of the respondents was directed towards differences in contributions and not, e.g., towards differences in needs. It may also be influenced by the fact that both our samples come from countries with a traditionally Bismarckian type of pension system, where benefits are indeed linked to contributions. More research is needed to distinguish these different interpretations.

This last issue suggests that it would be an interesting research topic to confront questionnaire results with actual decisions and institutions in different countries. Especially fruitful could be a deeper empirical study of the actual legal rules that have been implemented in different countries to solve real-world claims problems. These legal rules are generic and introduced in order to settle future distributional conflicts. They are set by political players who have no direct stakes in these future conflicts. It can therefore be expected that legal rules reflect, more than actual decisions in an unregulated environment, the prevailing fairness opinions in society.

\section{Conclusion}

We discussed in this paper the results of a questionnaire study concerning claims problems among Belgian and German students. The results are robust over the two samples. Two versions of the questionnaire were considered-the Firm version and the Pensions version-in which the same claims problems were presented in different economic contexts. The questionnaire setup allowed us to consider (1) the question of within-context consistency, i.e., the degree to which respondents apply the same rule for different claims problems in the same economic context, and (2) the question of between-context uniformity, i.e., the degree to which respondents propose the same awards vector for the same claims problem in different economic contexts.

To start with the latter question: responses were clearly more egalitarian in the Pensions version of the questionnaire than in the Firm version. We suggested that this phenomenon could be due to the fact that the Pensions context induced respondents to give more weight to respect for basic needs in the choice of awards vectors. The finding that the distributions chosen in different claims problems are dependent on the economic context of the problem is not new. From a theoretical point of view, it raises the difficult challenge of the construction of a kind of meta-theory that would give a formal structure to the relationship between the characteristics of the economic environment and the choice of a specific rule. Considerations of personal responsibility and differential needs will certainly play an important role here.

With regard to the question of within-context consistency, we found that the proportional rule performed very well in describing the choices of the respondents in both versions of the questionnaire. The other two rules that play a prominent role in the literature, viz., the constrained equal losses and constrained equal awards rules, fail to capture basic intuitions of the respondents. Respondents were reluctant to give a zero award to an individual with a nonzero claim. The constrained equal losses rule is 
the only of the eight considered rules that violates this property. ${ }^{14}$ Respondents also seemed to prefer to give a strictly higher award to an individual with a strictly higher claim. The constrained equal awards rule in many problems gives equal awards to individuals with different claims. With the notable exception of the proportional rule, all rules we considered violate this property in some cases, but not in as many cases as the constrained equal awards rule. ${ }^{15}$ Our results suggest that respondents are applying lower bounds on differences between awards, and it may be interesting to study such lower bounds formally.

We also considered the question of within-context consistency from the inequality perspective. The questionnaire design allowed us to examine variations in the tolerance of inequality of the respondents under simple changes of the characteristics of the claims problem. Of those respondents who did not adopt a uniform attitude towards inequality in all claims problems, a substantial percentage tend to become more progressive as the amount to divide decreases other things equal, and tend to become more progressive as the inequality of the claims vector increases other things equal. We see this result as an encouragement to document for each important rule how it behaves in terms of inequality under such simple changes of the characteristics of the claims problem. Such ideas are useful in organizing empirical intuitions concerning claims problems, but have remained largely unexamined in the theoretical literature. ${ }^{16}$

Open Access This article is distributed under the terms of the Creative Commons Attribution Noncommercial License which permits any noncommercial use, distribution, and reproduction in any medium, provided the original author(s) and source are credited.

\section{Appendix A: Definitions of rules}

We present formal definitions of the Talmud, Piniles', constrained egalitarian, random arrival, and minimal overlap rules.

The Talmud rule was proposed by Aumann and Maschler (1985) in order to rationalize examples found in the Babylonian Talmud. The rule attaches particular importance to the relative positions of the amount to divide $E$ and the sum of the half-claims $C / 2$. If $E=C / 2$, then each individual receives her half-claim. If $E<C / 2$, then the rule focuses on awards: it equalizes awards under the constraint that no individual receives an award that is greater than her half-claim. If $E>C / 2$, then the rule focuses on losses: it equalizes losses under the constraint that no individual receives an award that is smaller than her half-claim.

\footnotetext{
14 Recent studies address lower bounds on awards that imply nonzero awards for nonzero claims. An example is the requirement that no individual receives an award smaller than $1 / n$ times her claim truncated at the amount to divide (Moreno-Ternero and Villar 2004; Dominguez and Thomson 2006).

15 Young (1988) characterizes a class of rules that satisfy strict order preservation (among other properties) and contains the proportional rule.

16 An exception is the study of Hougaard and Østerdal (2005), which concerns the behaviour of the proportional rule under variations of the inequality of the claims vector. Several recent studies address other distributional aspects of rules: see the references in Sect. 2.
} 
Talmud rule, $\boldsymbol{T}$. For all $(c, E) \in \mathscr{C}$, we have that

(i) if $E \leq C / 2$, then $T(c, E)=C E A\left(\frac{1}{2} c, E\right)$,

(ii) if $E \geq C / 2$, then $T(c, E)=\frac{1}{2} c+C E L\left(\frac{1}{2} c, E-\frac{1}{2} C\right)$.

Typical awards vectors for the Talmud rule are $\left(\frac{1}{2} c_{1}, \frac{1}{2} c_{2}, \ldots, \frac{1}{2} c_{k}, \lambda, \lambda, \ldots, \lambda\right)$ if $E \leq C / 2$, and $\left(\frac{1}{2} c_{1}, \frac{1}{2} c_{2}, \ldots, \frac{1}{2} c_{k}, c_{k+1}-\lambda, c_{k+2}-\lambda, \ldots, c_{n}-\lambda\right)$ if $E \geq C / 2$.

Piniles' rule and the constrained egalitarian rule coincide with the Talmud rule whenever $E \leq C / 2$. Contrary to the Talmud rule, both rules focus on equality of awards if $E>C / 2$. Piniles' rule was introduced by Piniles (1861) in an early attempt to rationalize the numbers appearing in the Talmud. If $E>C / 2$, then the rule first gives each individual her half-claim. The remainder is divided equally under the constraint that no individual receives an award that exceeds her claim.

Piniles' rule, Pin. For all $(c, E) \in \mathscr{C}$, we have that

(i) if $E \leq C / 2$, then $\operatorname{Pin}(c, E)=T(c, E)=C E A\left(\frac{1}{2} c, E\right)$,

(ii) if $E \geq C / 2$, then $\operatorname{Pin}(c, E)=\frac{1}{2} c+C E A\left(\frac{1}{2} c, E-\frac{1}{2} C\right)$.

If $E>C / 2$, then $\left(c_{1}, c_{2}, \ldots, c_{k}, \frac{1}{2} c_{k+1}+\lambda, \frac{1}{2} c_{k+2}+\lambda, \ldots, \frac{1}{2} c_{n}+\lambda\right)$ is a typical awards vector for Piniles' rule.

The constrained egalitarian rule was proposed by Chun et al. (2001) who took as their inspiration the uniform rule (Sprumont 1991). If $E>C / 2$, then the rule equalizes awards under the constraint that no individual receives an award smaller than her half-claim or greater than her claim.

Constrained egalitarian rule, $\boldsymbol{C E}$. For all $(c, E) \in \mathscr{C}$, we have that

(i) if $E \leq C / 2$, then $C E(c, E)=T(c, E)=C E A\left(\frac{1}{2} c, E\right)$,

(ii) if $E \geq C / 2$, then, for all $i \in N$, we have $C E_{i}(c, E)=\max \left\{\frac{c_{i}}{2}, \min \left\{c_{i}, \lambda\right\}\right\}$ where $\lambda \in \mathbb{R}_{+}$is chosen so as to achieve efficiency.

If $E>C / 2$, then $\left(c_{1}, c_{2}, \ldots, c_{k}, \lambda, \lambda, \ldots, \lambda, \frac{1}{2} c_{\ell}, \frac{1}{2} c_{\ell+1}, \ldots, \frac{1}{2} c_{n}\right)$ is a typical awards vector for the constrained egalitarian rule.

The final two rules, both introduced in a pioneering paper by O'Neill (1982), coincide with the Talmud rule in the case of two claimants. The random arrival rule is closely related to the Shapley value. To define this rule, assume the individuals arrive one by one, each receiving full compensation until the money runs out. By averaging the awards vectors obtained in this way over all possible orders of arrival, we get the division recommended by the random arrival rule. Let $\Pi^{N}$ denote the class of all permutations of $N$.

Random arrival rule, $\boldsymbol{R A}$. For all $(c, E) \in \mathscr{C}$ and all $i \in N$, we have

$$
R A_{i}(c, E)=\frac{1}{n !} \sum_{\pi \in \Pi^{N}} \min \left\{c_{i}, \max \left\{E-\sum_{j \in N, \pi(j)<\pi(i)} c_{j}, \quad 0\right\}\right\} .
$$

The minimal overlap rule is an extension of a proposal by Ibn Ezra in the twelfth century (O’Neill 1982; Chun and Thomson 2005; Alcalde et al. 2008). To understand 
the rule, regard each individual $i$ as claiming the part $\left[0, c_{i}\right]$ of the interval $[0, E]$. The rule distinguishes two cases. (i) In the case where there exists an individual with a claim at least as great as the amount to divide, all claims are first truncated by the amount available. Next, each part of $[0, E]$ is divided equally among all individuals claiming it. For instance, the interval $\left[0, c_{1}\right]$ is claimed by everyone, and so everyone gets $c_{1} / n$. The interval $\left(c_{1}, c_{2}\right]$ is claimed by everyone except individual 1 , and so each member of $N-\{1\}$ receives in addition $\left(c_{2}-c_{1}\right) /(n-1)$. This process continues until the entire interval $[0, E]$ is covered. (ii) In the case where all individuals have claims smaller than the amount to divide, one lets $c_{0}=0$ and looks for the largest $k^{*}$ in $\{0,1,2, \ldots, n-2\}$ for which there exists a $t \in \mathbb{R}_{+}$that satisfies

$$
c_{k^{*}}<t \leq c_{k^{*}+1} \text { and }\left(c_{k^{*}+1}-t\right)+\left(c_{k^{*}+2}-t\right)+\cdots+\left(c_{n}-t\right)=E-t .{ }^{17}
$$

Each individual $i$ in the set $\left\{k^{*}+1, k^{*}+2, \ldots, n\right\}$ receives a first share equal to $c_{i}-t$, i.e., the part of the interval $(t, E]$ that $i$ alone claims. The remaining part $[0, t]$ is divided as in case (i) with $t$ as the amount to divide. For the definition, we follow Chun and Thomson (2005, p. 138).

Minimal overlap rule, $\boldsymbol{M O}$. Let $(c, E) \in \mathscr{C}$. We add a dummy, denoted by 0 , to the set of individuals and we put $c_{0}=M O_{0}=0$. Then, we have the following.

(i) Let $c_{k^{*}}<E \leq c_{k^{*}+1} \leq c_{n}$ with $k^{*} \in\{0,1,2, \ldots, n-1\}$. Then,

$$
\begin{aligned}
& M O_{i}=\frac{c_{1}}{n}+\frac{c_{2}-c_{1}}{n-1}+\frac{c_{3}-c_{2}}{n-1}+\cdots+\frac{c_{i}-c_{i-1}}{n-(i-1)} \quad \text { for each } i=1,2, \ldots, k^{*}, \\
& M O_{j}=M O_{k^{*}}+\frac{E-c_{k^{*}}}{n-k^{*}} \quad \text { for each } j=k^{*}+1, k^{*}+2, \ldots, n .
\end{aligned}
$$

(ii) Let $c_{n}<E$. Let $c_{k^{*}}<t \leq c_{k^{*}+1}$ with $k^{*} \in\{0,1,2, \ldots, n-2\}$ and $t$ as in (1). Then,

$$
\begin{aligned}
& M O_{i}=\frac{c_{1}}{n}+\frac{c_{2}-c_{1}}{n-1}+\frac{c_{3}-c_{2}}{n-1}+\cdots+\frac{c_{i}-c_{i-1}}{n-(i-1)} \quad \text { for each } i=1,2, \ldots, k^{*}, \\
& M O_{j}=\left(c_{j}-t\right)+M O_{k^{*}}+\frac{t-c_{k^{*}}}{n-k^{*}} \quad \text { for each } j=k^{*}+1, k^{*}+2, \ldots, n .
\end{aligned}
$$

\section{Appendix B: Description of categories}

Over two questions, the response patterns belonging to the categories same, decrease, and increase can be defined using the proportional rule, the constrained equal awards rule, and the constrained equal losses rule as benchmarks.

1. Same progressivity in question $x$ and question $y$ :

(a) Consistent with the constrained equal awards rule in question $x$ and in question $y$.

(b) Consistent with the proportional rule in question $x$ and in question $y$.

(c) Consistent with the constrained equal losses rule in question $x$ and in question $y$.

$\overline{17}$ If the claims happen to be feasible, i.e., $c_{1}+c_{2}+\cdots+c_{n}=E$, then $k^{*}=0$ and we allow $t=c_{0}=0$. 
2. Decrease of progressivity from question $x$ to question $y$ :

(a) Consistent with the constrained equal awards rule in question $x$ and less progressive than the constrained equal awards rule in question $y$.

(b) More progressive than the proportional rule in question $x$ and at most as progressive as the proportional rule in question $y$.

(c) Consistent with the proportional rule in question $x$ and less progressive than the proportional rule in question $y$.

(d) Less progressive than the proportional rule but not consistent with the constrained equal losses rule in question $x$ and consistent with the constrained equal losses rule in question $y$.

3. Increase of progressivity from question $x$ to question $y$ :

(a) Consistent with the constrained equal losses rule in question $x$ and more progressive than the constrained equal losses rule in question $y$.

(b) Less progressive than the proportional rule in question $x$ and at least as progressive as the proportional rule in question $y$.

(c) Consistent with the proportional rule in question $x$ and more progressive than the proportional rule in question $y$.

(d) More progressive than the proportional rule but not consistent with the constrained equal awards rule in question $x$ and consistent with the constrained equal awards rule in question $y$.

Over three questions, the five categories same, decrease, increase, decreaseincrease, and increase-decrease are defined as follows.

1. Same progressivity over questions $x, y, z$ : Same in $x$ and $y$ and same in $y$ and $z$.

2. Decrease of progressivity over questions $x, y, z$ :

(a) Decrease from $x$ to $y$ and decrease from $y$ to $z$.

(b) Decrease from $x$ to $y$ and same from $y$ to $z$.

(c) Same from $x$ to $y$ and decrease from $y$ to $z$.

3. Increase of progressivity over questions $x, y, z$ :

(a) Increase from $x$ to $y$ and increase from $y$ to $z$.

(b) Increase from $x$ to $y$ and same from $y$ to $z$.

(c) Same from $x$ to $y$ and increase from $y$ to $z$.

4. Decrease-increase of progressivity over questions $x, y, z$ : Decrease from $x$ to $y$ and increase from $y$ to $z$.

5. Increase-decrease of progressivity over questions $x, y, z$ : Increase from $x$ to $y$ and decrease from $y$ to $z$.

\section{References}

Alcalde J, Marco MC, Silva JA (2008) The minimal overlap rule revisited. Soc Choice Welf 31:109-128 Aumann RJ, Maschler M (1985) Game theoretic analysis of a bankruptcy problem from the Talmud. J Econ Theory 36:195-213

Béhue V (2003) Opinions éthiques sur les règles de division concernant les problèmes de banqueroute et de taxation. Mimeo, Université de Caen

Boeri T, Börsch-Supan A, Tabellini G (2001) Would you like to shrink the welfare state? A survey of European citizens. Econ Policy 32:9-50 
Boeri T, Börsch-Supan A, Tabellini G (2002) Pension reforms and the opinions of European citizens. Am Econ Rev (Papers and Proceedings) 92:396-401

Bosmans K, Lauwers L (2007) Lorenz comparisons of nine rules for the adjudication of conflicting claims. CES Discussion Paper 07.05, Katholieke Universiteit Leuven

Chun Y, Thomson W (2005) Convergence under replication of rules to adjudicate conflicting claims. Games Econ Behav 50:129-142

Chun Y, Schummer J, Thomson W (2001) Constrained egalitarianism: a new solution for claims problems. Seoul J Econ 14:269-297

Dominguez D, Thomson W (2006) A new solution to the problem of adjudicating conflicting claims. Econ Theory 28:283-307

Elster J (1992) Local justice. Cambridge University Press, Cambridge

Frohlich N, Oppenheimer J (1992) Choosing justice. University of California Press, Berkeley

Gächter S, Riedl A (2006) Dividing justly in bargaining problems with claims: normative judgments and actual negotiations. Soc Choice Welf 27:571-594

Herrero C, Moreno-Ternero JD, Ponti G (2006) On the adjudication of conflicting claims: an experimental study. CORE Discussion Paper 2006/62, Université catholique de Louvain

Hougaard JL, Østerdal LP (2005) Inequality preserving rationing. Econ Lett 87:355-360

Hougaard JL, Thorlund-Petersen L (2001) Bankruptcy rules, inequality, and uncertainty. Working Paper 4/01, Department of Operations Management, Copenhagen Business School

Ju B-G, Moreno-Ternero JD (2008) On the equivalence between progressive taxation and inequality reduction. Soc Choice Welf 30:561-569

Konow J (2003) Which is the fairest one of all? A positive analysis of justice theories. J Econ Lit 41: 1188-1239

Moreno-Ternero JD, Villar A (2004) The Talmud rule and the securement of agents' awards. Math Soc Sci 47:245-257

Moreno-Ternero JD, Villar A (2006) On the relative equitability of a family of taxation rules. J Public Econ Theory 8:283-291

Moulin H (2002) Axiomatic cost and surplus sharing. In: Arrow KJ, Sen AK, Suzumura K (eds) Handbook of social choice and welfare, vol 1. Elsevier, Amsterdam, pp 289-357

O’Neill B (1982) A problem of rights arbitration from the Talmud. Math Soc Sci 2:345-371

Piniles HM (1861) Darkah shel Torah. Forester, Vienna

Schokkaert E (1999) M. Tout-le-monde est "post-welfariste:” opinions sur la justice redistributive. Rev Econ 50:811-831

Schokkaert E, Overlaet B (1989) Moral intuitions and economic models of distributive justice. Soc Choice Welf 6:19-31

Sen AK, Foster JE (1997) On economic inequality, expanded edition. Clarendon Press, Oxford

Sprumont Y (1991) The division problem with single-peaked preferences: a characterization of the uniform allocation rule. Econometrica 49:509-519

Thomson W (2003) Axiomatic and game-theoretic analysis of bankruptcy and taxation problems: a survey. Math Soc Sci 45:249-297

Thomson W (2008) Lorenz rankings of rules for the adjudication of conflicting claims. Mimeo

Young HP (1988) Distributive justice in taxation. J Econ Theory 44:321-335

Young HP (1994) Equity: in theory and practice. Princeton University Press, Princeton 